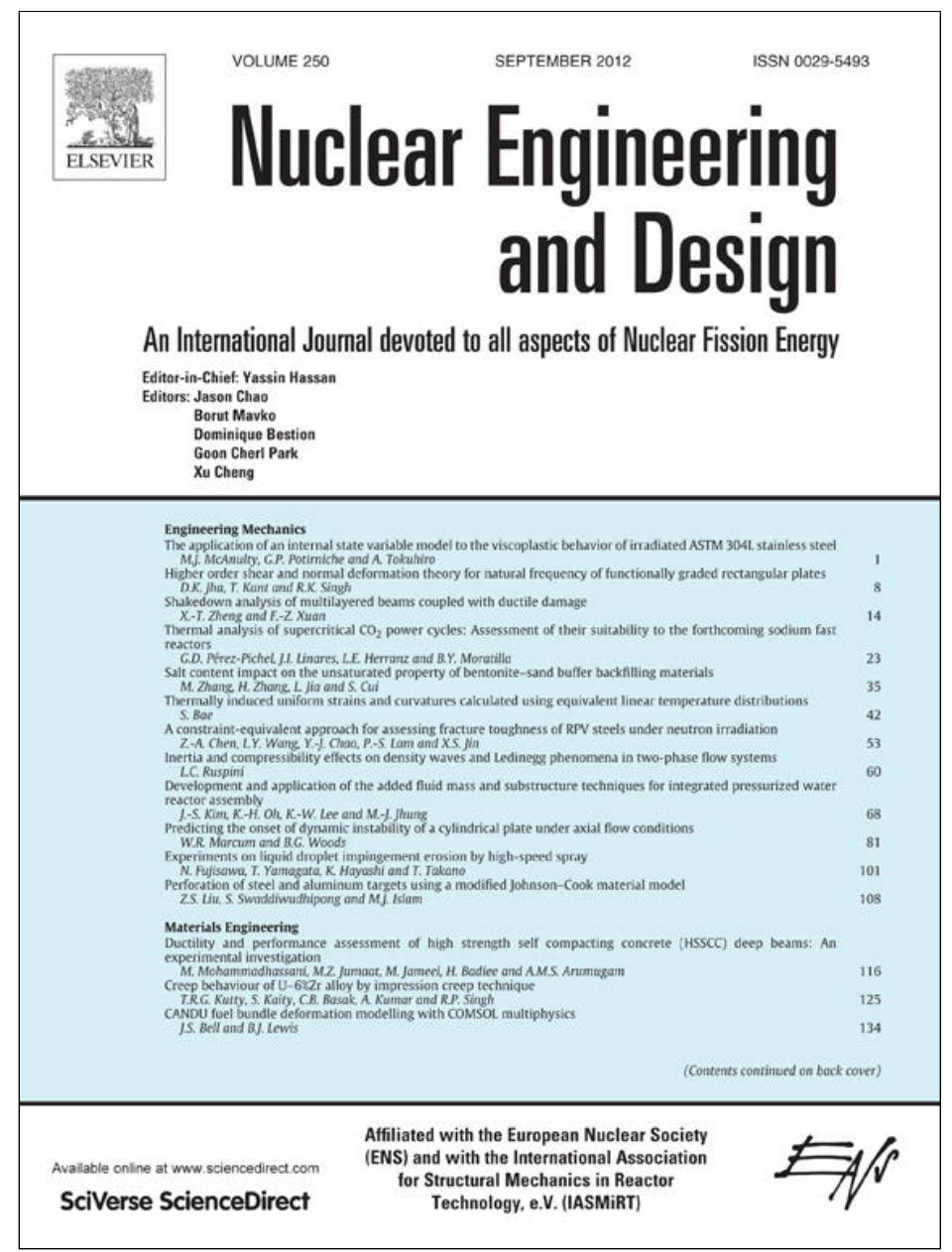

This article appeared in a journal published by Elsevier. The attached copy is furnished to the author for internal non-commercial research and education use, including for instruction at the authors institution and sharing with colleagues.

Other uses, including reproduction and distribution, or selling or licensing copies, or posting to personal, institutional or third party websites are prohibited.

In most cases authors are permitted to post their version of the article (e.g. in Word or Tex form) to their personal website or institutional repository. Authors requiring further information regarding Elsevier's archiving and manuscript policies are encouraged to visit:

http://www.elsevier.com/copyright 


\title{
An evaluation on fatigue crack growth in a fine-grained isotropic graphite
}

\author{
Hongtao Wang ${ }^{\mathrm{a}}$, Libin Sun ${ }^{\mathrm{a}}$, Chenfeng $\mathrm{Li}^{\mathrm{b}}$, Li Shi ${ }^{\mathrm{a}}$, Haitao Wang ${ }^{\mathrm{a}, *}$ \\ a Institute of Nuclear and New Energy Technology, Tsinghua University, Beijing 100084, China \\ b College of Engineering, Swansea University, Singleton Park, Swansea SA2 8PP, United Kingdom
}

\section{H I G H L I G H T S}

- The propagation of micro- and macro-fatigue cracks in IG-11 graphite was studied.

- The curves of the fatigue crack growth rate versus the SIF range show three stages.

- The fatigue microcrack propagation is very sensitive to graphite's microstructures.

- Graphite's microstructures have no significant impact on fatigue macrocrack growth.

- The fatigue fracture surface indicates the fracture mechanism of the IG-11 graphite.

\section{A R T I C L E I N F O}

\section{Article history:}

Received 3 November 2011

Received in revised form 21 February 2012

Accepted 29 May 2012

\begin{abstract}
A B S T R A C T
The aim of this paper is to investigate the mechanism of fatigue crack propagation in IG-11 graphite, and determine the crack growth rate in relation to the stress level. Experimental studies were performed at both micro and macro scales. For fatigue microcrack propagation, single-edge-notch specimens were chosen for testing and the fatigue crack growth was measured in situ with a scanning electron microscope. For fatigue macrocrack propagation, CT specimens were used and the fatigue crack growth was measured with a high-accuracy optic microscope. Combining the two groups of experimental results, the following conclusions are derived:

(1) The heterogeneous microstructures of the graphite material have significant impact on the fatigue microcrack growth, while their influence on fatigue macrocrack growth is very limited.

(2) The relationship between the fatigue crack growth rate and the crack-tip stress intensity factor range can be expressed in the form of Paris formulae, which contains three stages: an initial rising part with a small slope, an abrupt rise with a very large acceleration, and a short final part with a small slope.

(3) The fatigue fracture surface of the graphite material contains considerable sliding of leaf-shape graphite flakes combined with small cotton-shape plastic deformations. These sliding traces are approximately aligned at $45^{\circ}$, showing the main cause of the fatigue fracture is the shear stress. There are also a large amount of secondary cracks inside unit cells and on cell walls, which indicates the fracture mechanism of the IG-11 graphite is mainly cleavage fracture.
\end{abstract}

() 2012 Elsevier B.V. All rights reserved.

\section{Introduction}

Graphite materials have been widely used as fuel blocks and reactor internals in high-temperature gas-cooled reactors (HTGRs) due to their good characteristics of high temperature resistance and neutron moderation (Wu et al., 2002). For example, nuclear graphite IG-110, manufactured by Toyo Tanso Co., Ltd., Japan, has been used to produce fuel blocks and replaceable reflector blocks in the high temperature engineering test reactor (Saito et al., 1994; Wang et al., 2009), a graphite-moderated gas-cooled

\footnotetext{
* Corresponding author. Tel.: +86 106279 7882, fax: +86106279 7136 . E-mail addresses: wanght@tsinghua.edu.cn, wanght@mail.tsinghua.edu.cn (H. Wang).
}

reactor at Japan Atomic Energy Research Institute (JAERI). During the startup, operation and shutdown of a reactor, reactor internals may encounter with different fatigue loads caused by pressure fluctuations from the helium coolant and dimensional changes due to neutron damage and thermal stresses. Microscopic cracks and flaws inevitably exist in the graphite, and these cyclic external and internal loads may cause initiation and propagation of micro- and macro-cracks. Therefore, fatigue and fracture analysis of graphite are essential for the life prediction of reactor internals in HTGRs.

Many researchers have investigated the fatigue and fracture behavior of different graphite materials. As no formal standard has been established for testing graphite materials, different test methods and specimen configurations have been used in the literature, and in some cases there also exist significant difference between experimental results. Using straight-through-precracked 
and straight-through-notched specimens, the fracture toughness of IG-110 graphite was studied (Li et al., 1999). The precrack propagated straight-through, i.e. perpendicular to the loading direction at the macro scales, and exhibited a zigzag mode at the micro scale. This indicates that the microstructure and the grain size and shape have significant influence on the propagation path of microcracks. Using three-point bending and compact tension (CT) tests, the fracture toughness and $R$-curve behavior of three commercial grade nuclear graphites (including IG-110 graphite) were obtained (Fazluddin, 2002). The sandwiched beam in three-point bending was applied to IG-110 graphite to assess its suitability for determining the fracture toughness and R-curve behavior of nuclear graphite materials (Shi et al., 2008). Using modified CT specimens, the crack propagation in nuclear graphites and the mechanisms of the R-curve behavior were investigated based on X-ray tomography in situ observation (Hodgkins et al., 2004, 2006). Crack growth resistance curves for PGA and IM1-24 graphites were obtained in Ouagne et al. (2002), which contain an initial rising part, followed by a plateau region indicating the critical values of fracture parameters. The crack bridging in the weak region of IM1-24 and PGA graphites implies that crack propagation (especially the crack growth path in the microscopic region) is complex and varies dramatically even under the low cyclic loading condition. The effects of stress ratio, oxidation, specimen volume and cumulative damage on fatigue behavior and fracture toughness of IG-110/IG-11 and PGX graphites were studied in Shintarou et al. (1991). The results show that the crack growth rate of IG-11 graphite can be expressed as the Paris formula, in which the threshold of the stress intensity factor (SIF) range depends on the stress ratio. Using CT specimens, the fatigue crack growth rates of two graphites under different SIF ranges were obtained in (Marshall and Priddle, 1973), and the results were expressed as the Paris formula with a threshold. The fatigue crack growth rates of IG-11 and SM1-24 graphites were studied in Kakui and Oku (1986) using DCB (double cantilever beam) specimens, and the results were also expressed as the Paris formula but without a threshold. ATR-2E and ASR-IRS graphites were tested in (Thiele et al., 1983) using CT specimens, and the fatigue crack growth rates were expressed as a complex formula. Using DCB specimens, the fatigue and impact behavior of two graphites used in the advanced gas cooled reactor (AGR) were examined (Shaw and Bacon, 1993), and the fatigue crack growth rates were expressed as the Paris formula both with and without a threshold, where the ratio of the SIF over the fracture toughness was used to describe the fatigue load.

Although the above research works have focused on fracture analysis and crack propagation of graphites, the mechanism of the associated fatigue failure was less studied, especially very few reports can be found for the initiation and propagation of microcracks in graphite materials. The aim of this paper is to determine the fatigue crack growth rate of IG-11 graphite under different loading conditions, and to study the effect of the microstructure on fatigue crack propagation. The results will be useful for the design of reactor internals in HTGRs.

\section{Experimental materials and methods}

IG-11 graphite, manufactured by Toyo Tanso Ltd., Japan, is a finegrained isotropic petroleum coke-based polycrystalline graphite made by the isostatic pressing method. IG-11 graphite is the non-purified counterpart of the nuclear graphite IG-110. Its microstructural characteristics include the mean size of petroleum coke grain of $14 \mu \mathrm{m}$, the mean pore size of $3 \mu \mathrm{m}$ and the porosity of $15 \%$ ( $\mathrm{Li}$ et al., 1999). Some typical material properties of IG-11 graphite are listed in Table 1. Detailed information of the fracture
Table 1

Typical material properties of IG-11 graphite (Saito et al., 1994; Wang et al., 2009; Zhou et al., 2011).

\begin{tabular}{llc}
\hline Property & Unit & Value \\
\hline Mean compressive strength & $\mathrm{MPa}$ & 76.8 \\
Mean tensile strength & $\mathrm{MPa}$ & 25.3 \\
Mean bending strength & $\mathrm{MPa}$ & 37.2 \\
Young's modulus & $\mathrm{GPa}$ & 10.2 \\
Poisson's ratio & & 0.17 \\
Bulk density & $\mathrm{g} / \mathrm{cm}^{3}$ & 1.76 \\
Mean thermal expansion coefficient $\left(20-400^{\circ} \mathrm{C}\right)$ & $\times 10^{-6} \mathrm{~K}^{-1}$ & 4.06 \\
\hline
\end{tabular}

mechanics behavior can be found in Li et al. (1999), Fazluddin (2002) and Shintarou et al. (1991).

In order to obtain a full picture of crack initiation and propagation in the graphite material, both micro- and macro-cracks are studied in this work. Due to the scale difference of the two kinds of cracks, the loading equipments, the size and shape of specimens and the measurement methods are all different. For the study of fatigue microcracks, single-edge-notch specimens are loaded on a servo fatigue testing machine, and the length of microcracks is measured in situ with a scanning electron microscope (SEM). In the microcrack experiments, the crack propagation has been limited within $100 \mu \mathrm{m}$. For the fatigue macrocrack testing, CT specimens are used and they are tested on a fatigue testing machine. The length of macrocracks is measured by using an optical microscope with an observation capacity of $0.1 \mathrm{~mm}$.

Although the initiation and propagation of micro- and macrocracks are often observed differently, their underlying mechanisms are closely related. The objective of investigating microcracks is to determine whether the initiation of microcracks is related to the micro-structure of the graphite material, and what influence it has on the mechanical behavior of macrocracks. For macrocracks, we will evaluate the fatigue crack growth rate, which can be directly used as the fatigue failure criterion in engineering applications.

\section{Fatigue microcrack tests using in situ SEM}

\subsection{Experimental method}

The experimental system used for the loading and observation of fatigue microcracks mainly includes two parts: the hydraulic loading system and the Shimadzu SS550 SEM. As shown in Fig. 1, the specimen was made into a flat dog-bone shape, and the specimen surface was fine polished for better observation of the microstructure and crack propagation. To help observation and tracking of microcrack propagation, a notch at a radius of about $900 \mu \mathrm{m}$ was added to each specimen, creating a localized stress concentration domain during loading. The depth of the notch is about $500 \mu \mathrm{m}$. At the testing area around the notch, the width of the specimen is $3 \mathrm{~mm}$ and the thickness is $3 \mathrm{~mm}$.

The fatigue crack growth tests were performed in the chamber of the SEM using a specially designed servo-hydraulic testing system. This machine provided pulsating (triangular wave) loads at $1 \mathrm{~Hz}$ of $\pm 1 \mathrm{kN}$ maximum capacity and a displacement range of $\pm 25 \mathrm{~mm}$. The signal of the SEM was directly transferred to a computer via a direct memory access type A/D converter, which supports sampling-resolution $960 \times 1280$ for SEM images. The SEM was operated at an accelerating voltage of $15 \mathrm{kV}$. All fatigue tests were load controlled at a stress ratio of $R=0.1\left(R=\sigma_{\min } / \sigma_{\max }\right)$. The lengths of fatigue microcracks were directly measured with the calibrated scale of SEM. It is noted that the SEM measurement represents only the length of surface cracks, if the microcrack propagates differently along the thickness direction of the specimen. The initiation and propagation of fatigue microcracks were recorded at a frequency of $0.1-0.5 \mathrm{~Hz}$, but between observations the frequency 

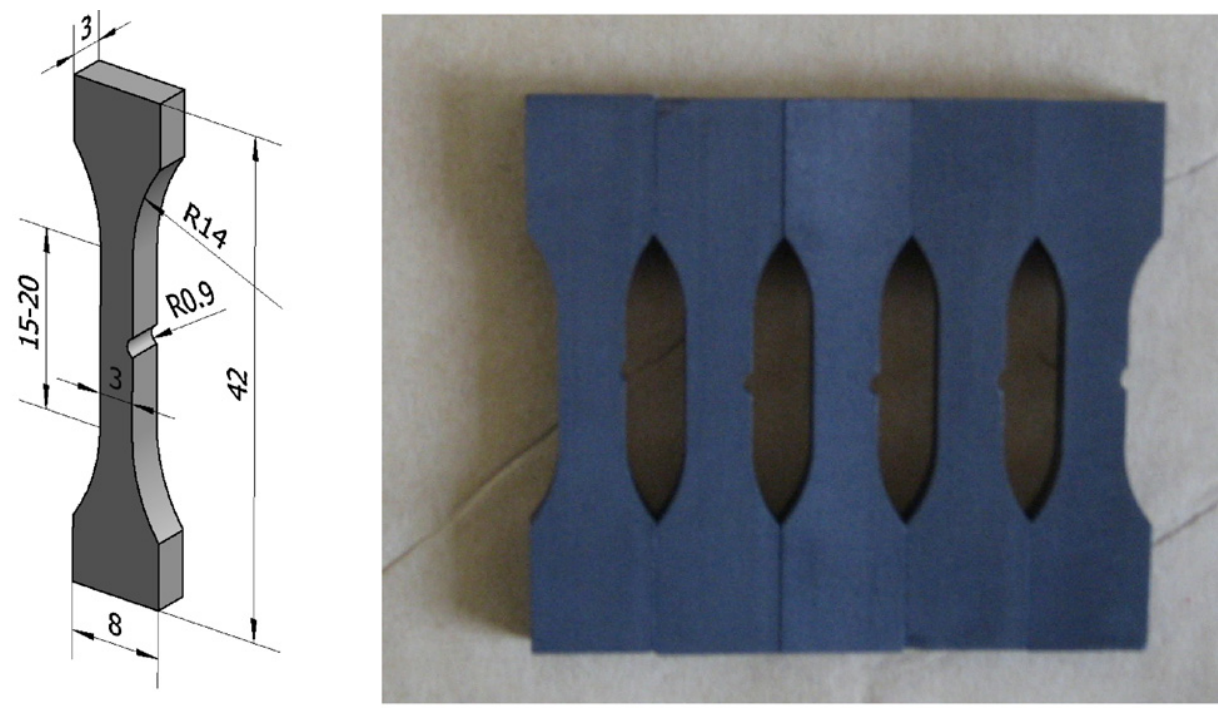

(a) Schematic illustration of the specimen

(b) Real picture of the specimen

Fig. 1. The single-edge-notch specimen used in the study of fatigue microcracks.

was increased to $1 \mathrm{~Hz}$ to accelerate fatigue damage of the graphite. The above fatigue testing design has been verified in several other applications (Wang and Fan, 2006; Li and Zhang, 2001; Wang and Fan, 2004; Wang et al., 2004, 2006; Wang and Li, 2003; Wang and $\mathrm{Xu}, 2004$ ) involving cast magnesium alloys, $\mathrm{U}_{3} \mathrm{Si}_{2}-\mathrm{Al}$ fuel plate and powder metallurgy alloys specimens.

\subsection{Investigation of fatigue microcracks}

In order to understand the mechanism of microcrack initiation and propagation, ten single-edge-notch specimens were tested, and the maximum nominal stress at the notch was controlled at $8 \mathrm{MPa}, 10 \mathrm{MPa}$ and $12 \mathrm{MPa}$. A great extent of divergence was found in the test results. For the $8 \mathrm{MPa}$ and $10 \mathrm{MPa}$ tests, almost all specimens survived beyond $5 \times 10^{5}$ cycles. For the $12 \mathrm{MPa}$ testing, six specimens failed immediately upon loading, three specimens did not fail virtually showing an infinite fatigue life, and only in one specimen was stable microcrack propagation observed. Due to the heterogeneous microstructure of the graphite material, the variation of fatigue microcrack behavior was not completely unexpected. IG-11 graphite has various random microstructures as shown in Fig. 2. For the specimens shown in Fig. 2(a and b), significant flaws and dispersed microcracks are observed in the vicinity of the notch, while for the specimen shown in Fig. 2(c), the material near the notch is almost intact. The initiation and propagation of microcracks are inevitably influenced by these randomly distributed microstructures, causing dramatic variations in the testing results. If a specimen happens to contain large flaws or groups of microcracks in the stress concentration area, it can potentially break very quickly upon loading; and if there happen to be no flaws in the stress concentration area, a very large fatigue life (above $5 \times 10^{5}$ cycles) could be observed under the same level of loading.

Shown in Fig. 3 is a typical stable microcrack propagation observed in one specimen. It can be seen that apart from the main microcrack, there are no other flaws or microcracks near the notch. This is why the stable crack propagation could be observed.

In Fig. 4, the microcrack length is plotted against the number of cycles. It can be seen that the relationship between the logarithm of microcrack length and the number of cycles is nonlinear as a whole, but for the first part up to $2 \times 10^{4}$ cycles, an approximate linear relationship can be assumed. That is

$\log \ell \propto N \Rightarrow \frac{d \ell}{d N} \propto \ell$

where $\ell$ denotes the length of the microcrack and $N$ denotes the number of load cycles. In Fig. 4 , the data diverge from a linear line in the second part. This is mainly because the microcrack starts to propagate in a kinked manner after the number of cycles increases to over $2 \times 10^{4}$ cycles. Similar crack extension path was also observed in Ouagne et al. (2002).

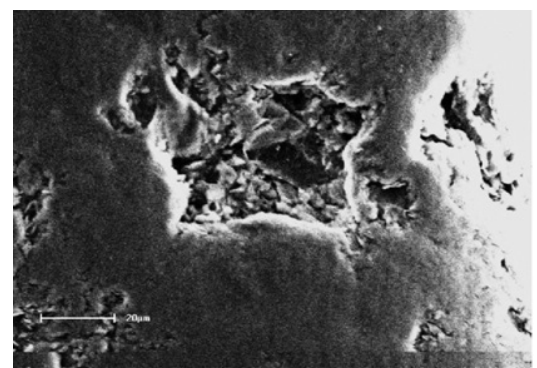

(a)

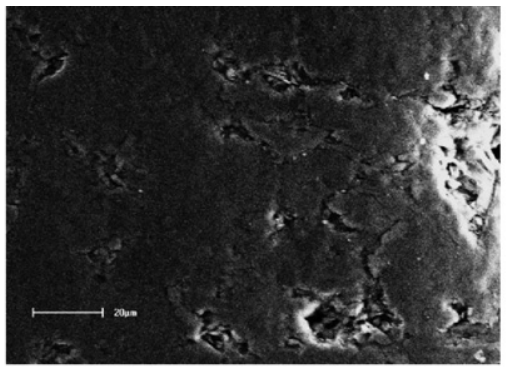

(b)

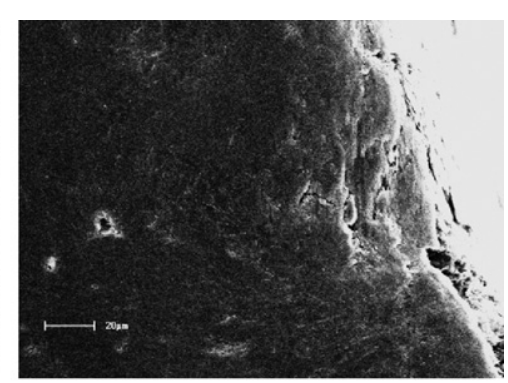

(c)

Fig. 2. Hetergeneous microstructure at the vicinity of the notch in different graphite specimens. 


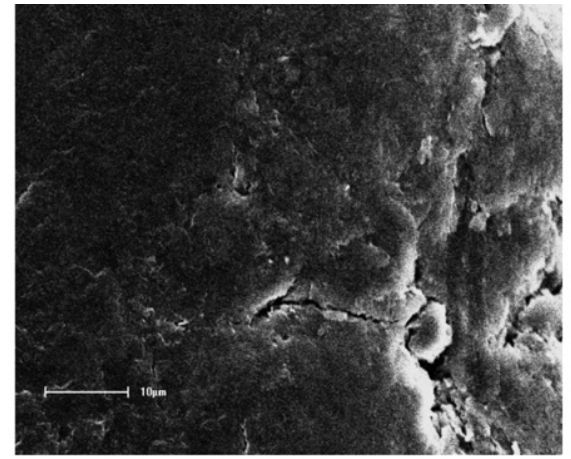

(a) $\mathrm{N}=2346$ (measuring scale $10 \mu \mathrm{m}$ )

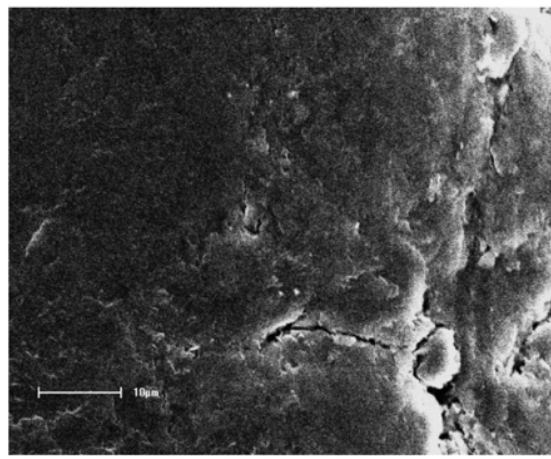

(b) $\mathrm{N}=4670$ (measuring scale $10 \mu \mathrm{m}$ )

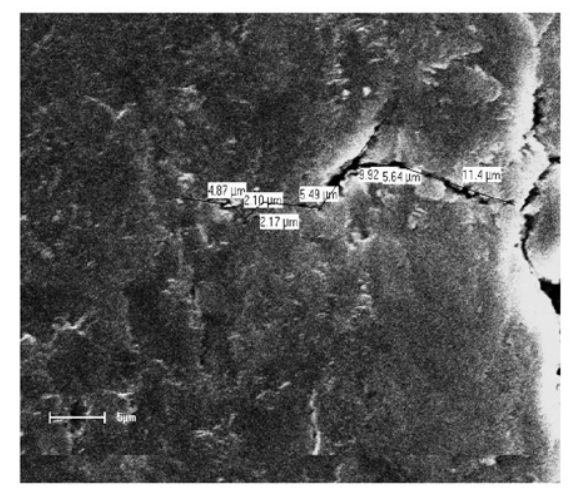

(c) $\mathrm{N}=13551$ (measuring scale $5 \mu \mathrm{m}$ )

Fig. 3. SEM images of fatigue microcrack propagation after different load cycles

As the SIF range is determined by the microcrack length $\ell$, the microcrack growth rate $d \ell / d N$ in Eq. (1) can also be linked to the SIF range, as shown in Fig. 5. The fitted curve can be expressed as:

$\frac{d \ell}{d N}=6.0 \times 10^{-9} \Delta K^{0.84}$

where $\Delta K$ is the SIF range of the single-edge-notch specimen, which can be defined as:

$\Delta K=\Delta \sigma \sqrt{\pi(b+\ell)} F\left(\frac{\ell}{W}\right)$

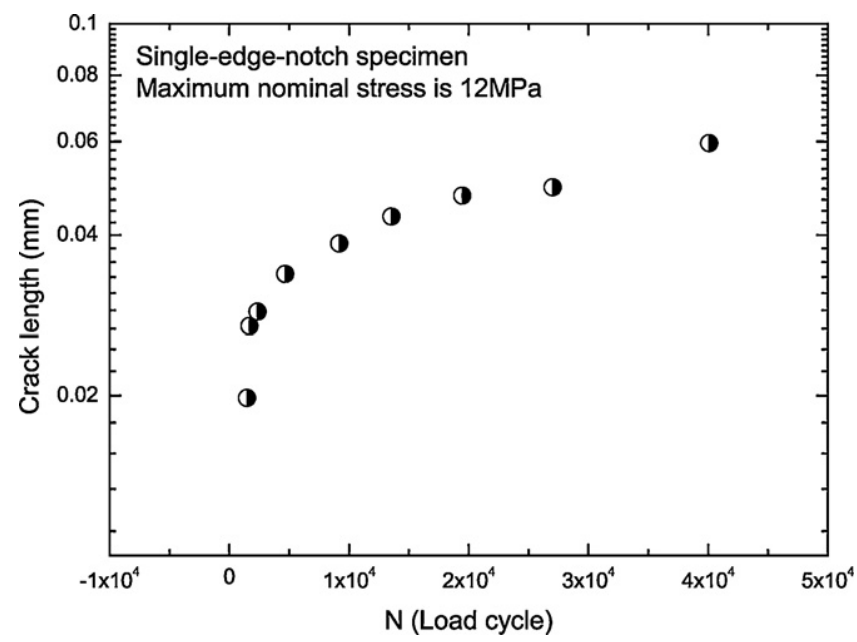

Fig. 4. Relationship between the microcrack length and the number of load cycles. where $\Delta \sigma$ is the stress range, $W$ is the width of the specimen, and the function of $F(\ell / W)$ can be found in Wang and Fan (2006).

\section{Fatigue macrocrack tests using CT specimens}

\subsection{Experimental method}

CT specimens were used in the study of fatigue macrocracks, and they were fabricated following the general ASTM E647 standard. The detailed geometry of the CT specimen is shown in Fig. 6,

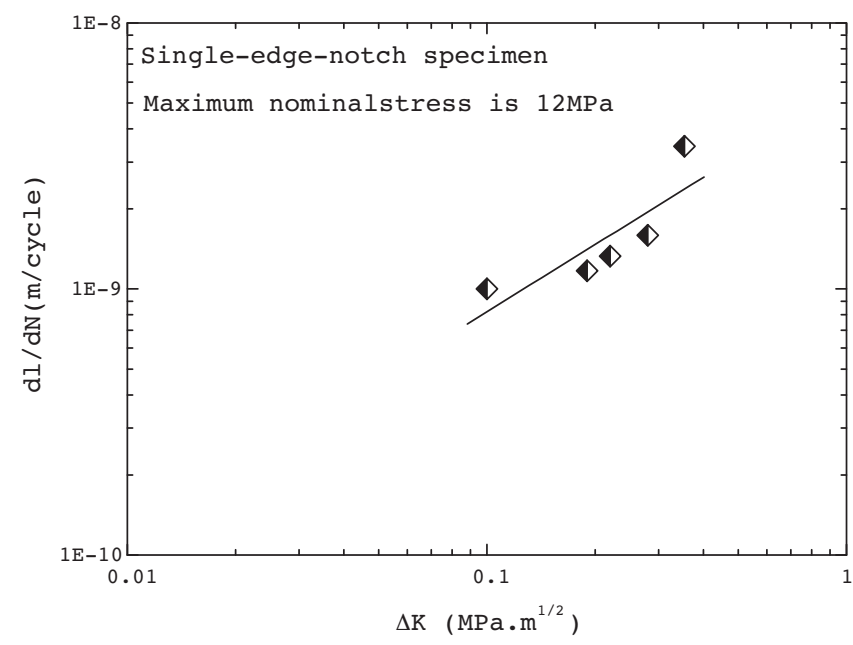

Fig. 5. The relationship between the fatigue microcrack growth rate and the SIF range. 


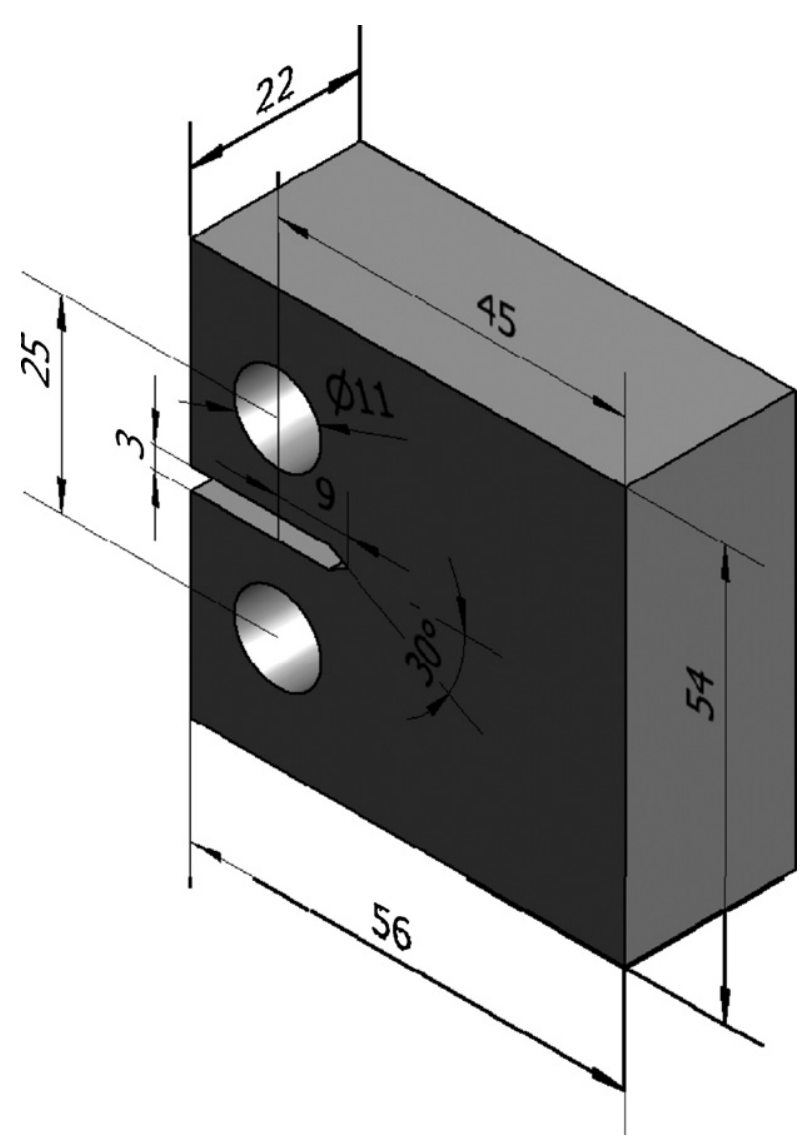

Fig. 6. CT specimen used in the fatigue macrocrack testing.

where the key dimensions are $W=45 \mathrm{~mm}$ and $B=22 \mathrm{~mm}$. The thickness $B$ was set sufficiently large to ensure the plane strain mode in most regions of the crack surface. The specimen surfaces were also polished to ensure clear observation of macrocracks up to $0.1 \mathrm{~mm}$.

Crack propagation is largely determined by the local stress concentration at crack tips. As graphite is brittle material, the fatigue crack growth rate can be related to the crack-tip stress-intensity factor range. Following ASTM E647 standard, the crack-tip SIF range of CT specimens can be expressed as:

$\Delta K=\frac{\Delta P(2+\alpha)}{B \sqrt{W}(1-\alpha)^{3 / 2}}\left(0.886+4.64 \alpha-13.31 \alpha^{2}+14.72 \alpha^{3}-5.6 \alpha^{4}\right)$

$\alpha=\frac{\ell}{W}$

where $\Delta P$ denotes the load range and $\ell$ denotes the fatigue crack length.

The CT specimen was loaded on an Instron 8874 fatigue testing machine with a maximum loading capacity of $50 \mathrm{kN}$. All fatigue tests were load controlled at a stress ratio of $R=0.1$. The crack length was measured using an optical microscope. The objective is to find the relationship between the fatigue crack growth rate and the SIF range.

\subsection{Experimental results of macrocracks}

After a series of cyclic loadings, the macrocrack propagated inside the CT specimen. A typical specimen is shown in Fig. 7, in which the whole crack is about $30 \mathrm{~mm}$ in length, with a thinner crack growth path, about $10 \mathrm{~mm}$, near the crack tip.

The relationships between the fatigue macrocrack length and the number of load cycles under different load levels are shown in Fig. 8. When the maximum load is $900 \mathrm{~N}$, the logarithm of the

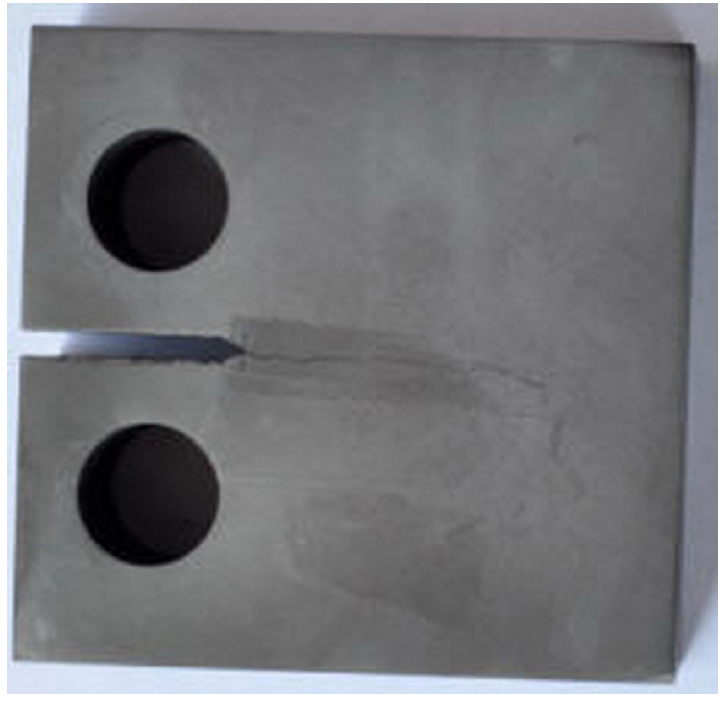

Fig. 7. Macrocrack inside a CT specimen.

macrocrack length is approximately proportional to the number of load cycles as shown in Fig. 8(a). The linear relationship holds particularly well for the first part of the data set where the number of load cycles is below $2 \times 10^{5}$. As the number of cycles increases $\left(2 \times 10^{5}<\mathrm{N}<5 \times 10^{5}\right)$, the speed of macrocrack propagation drops, and the maximum crack length is about $6.6 \mathrm{~mm}$. When the maximum load increases to $1000 \mathrm{~N}$, the macrocrack propagates very fast, and the macrocrack length reaches about $30 \mathrm{~mm}$, within tens of load cycles. In Fig. 8(a), the slope of crack propagation corresponding to $1000 \mathrm{~N}$ is much higher than the slope corresponding to $900 \mathrm{~N}$, indicating a much higher speed of crack propagation for the higher load level. The maximum crack length in the $1000 \mathrm{~N}$ case is also much higher than the $900 \mathrm{~N}$ case. In order to better understand the dramatic change taking place in the fracturing processes of these two loading cases, a loading case of $970 \mathrm{~N}$ was then tested, and the result is also plotted in Fig. 8(a). When the load is higher than $1000 \mathrm{~N}$, the macrocrack propagation cannot be easily observed under the traditional way of applying cyclic loads. Therefore, for the maximum load of $1050 \mathrm{~N}$, we applied the cyclic load statically, and the cyclic frequency was $0.1 \mathrm{~Hz}$. A macrocrack initiated suddenly after the sixth load cycle, and the CT specimen broke after the 12th load cycle. The fitted curve in Fig. 8(b) shows a linear relationship between the macrocrack length and the applied load cycles.

The fatigue macrocrack growth rate can be determined by the ratio of the incremental fatigue macrocrack length over the incremental number of load cycles. The SIF range $\Delta K$ can be calculated following Eq. (4). Thus, the relationship between the fatigue macrocrack growth rate and $\Delta K$ under different load levels can be obtained as shown in Fig. 9. These curves are approximately linear in double logarithmic coordinates, so that the relationship between the fatigue macrocrack growth rate and the SIF range $\Delta K$ can be expressed as follows:

$$
\frac{d \ell}{d N}=C \Delta K^{n}
$$

where the constants $C$ and $n$ can be determined from the experimental data. For different loading cases, the values of $C$ and $n$ are listed in Table 2 . It can be seen that the $C$ value increases by almost three orders of magnitude when the applied stress exceeds $15 \mathrm{MPa}$.

In order to check the repeatability of the experimental results, we repeated the tests twice for the CT specimen under the maximum load of $970 \mathrm{~N}$. The curves of the fatigue macrocrack length and the fatigue macrocrack growth rate are plotted in Figs. 10 and 11, 


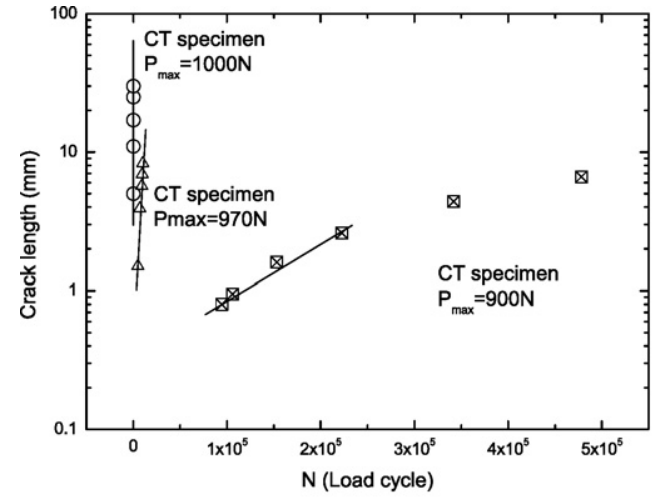

(a) The maximum loads are $900 \mathrm{~N}, 970 \mathrm{~N}$ and $1000 \mathrm{~N}$

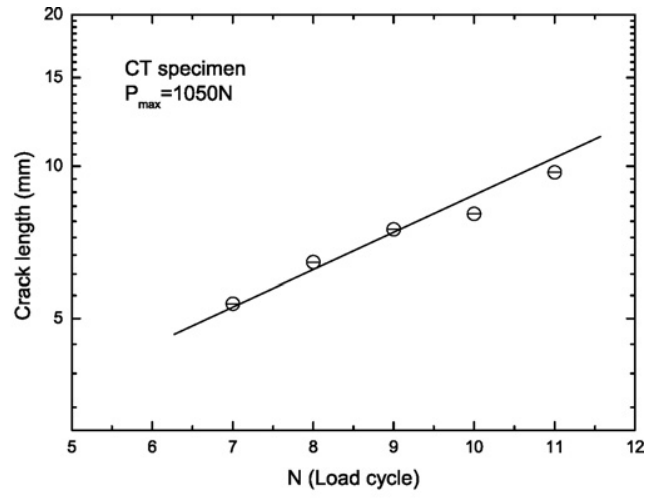

(b) The maximum load is $1050 \mathrm{~N}$

Fig. 8. The relationships between the fatigue macrocrack length and the number of cycles under different loads.

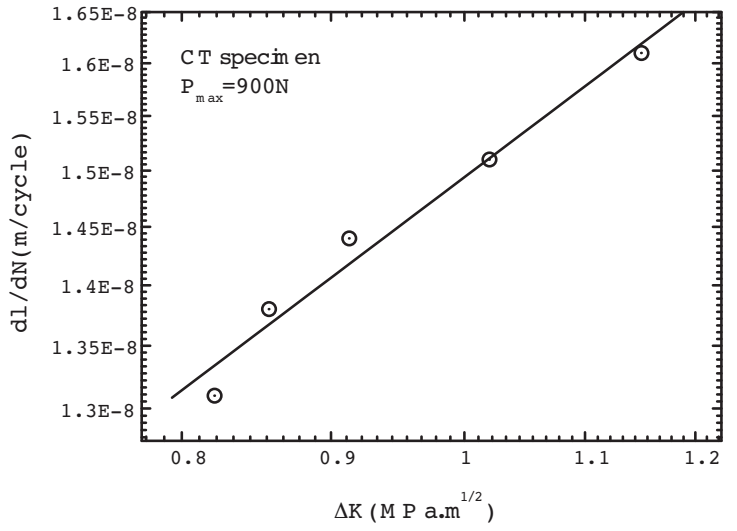

(a) The maximum load is $900 \mathrm{~N}$

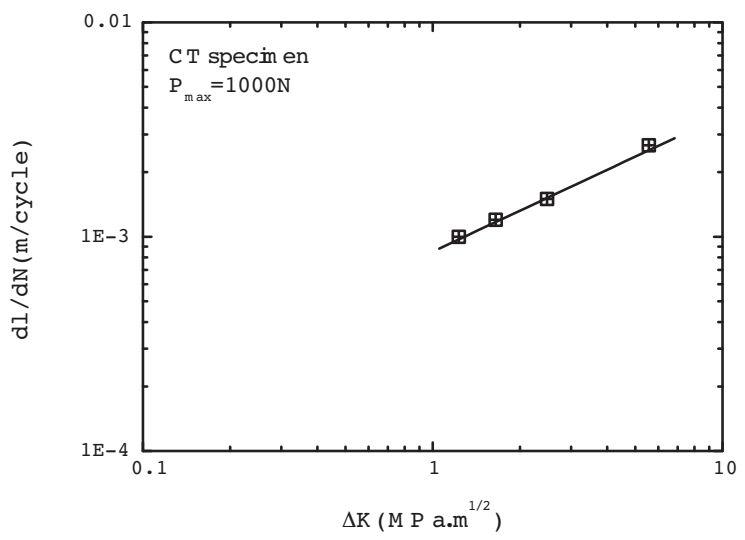

(c) The maximum load is $1000 \mathrm{~N}$

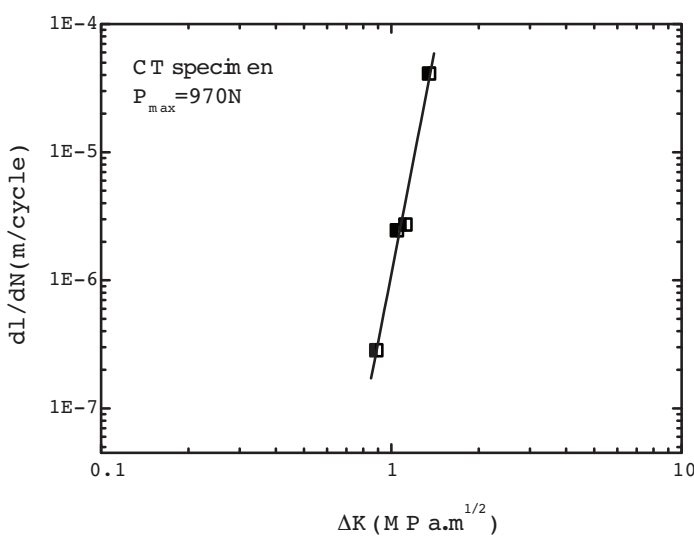

(b) The maximum load is $970 \mathrm{~N}$

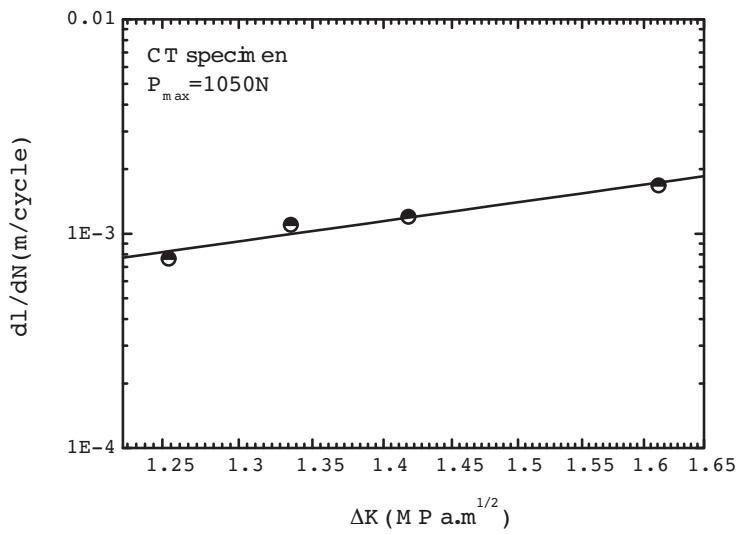

(d) The maximum load is $1050 \mathrm{~N}$

Fig. 9. The relationship between the fatigue macrocrack growth rate and the SIF range $\Delta K$ under different load levels.

Table 2

Constant parameters for the fatigue macrocrack growth rate under different loads.

\begin{tabular}{lllr}
\hline Load level $(\mathrm{N})$ & Reference stress $(\mathrm{MPa})$ & \multicolumn{2}{l}{$d \ell / d N=C \Delta K^{n}$} \\
\cline { 3 - 4 } & & \multicolumn{1}{l}{$\mathrm{C}$} & \multicolumn{1}{l}{$n$} \\
\hline & 12.00 & $6.0 \times 10^{-9}$ & 0.840 \\
900 & $10.26 \pm 1.11$ & $1.50 \times 10^{-8}$ & 0.574 \\
970 & $11.21 \pm 1.19$ & $1.12 \times 10^{-6}$ & 11.680 \\
1000 & $15.52 \pm 1.23$ & $8.71 \times 10^{-4}$ & 0.649 \\
1050 & $15.78 \pm 1.29$ & $4.27 \times 10^{-4}$ & 2.940 \\
\hline
\end{tabular}

respectively. A large difference is observed in the fatigue macrocrack propagation length for different CT specimens, as shown in Fig. 10. This is partially caused by the difference in the shape and size of the prefabricated notch. Another main cause to the data divergence is the porosity of the graphite material at the vicinity of the notch. For the repeated tests, the relationships between the fatigue macrocrack growth rate and the SIF range are plotted in Fig. 11. In double logarithmic coordinates, these data are aligned approximately along a linear line. The slope of the fitted straight 


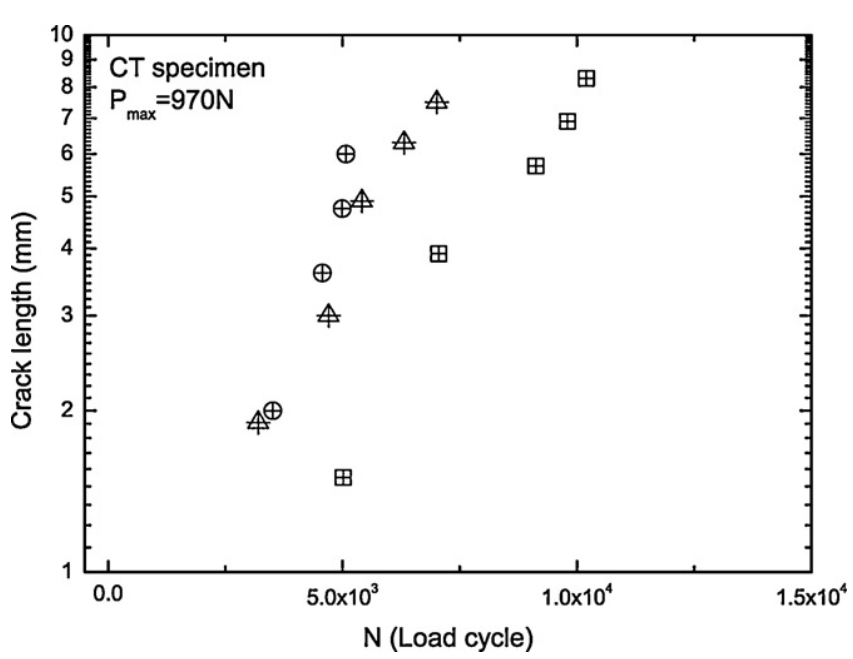

Fig. 10. The fatigue macrocrack length versus the number of load cycles.

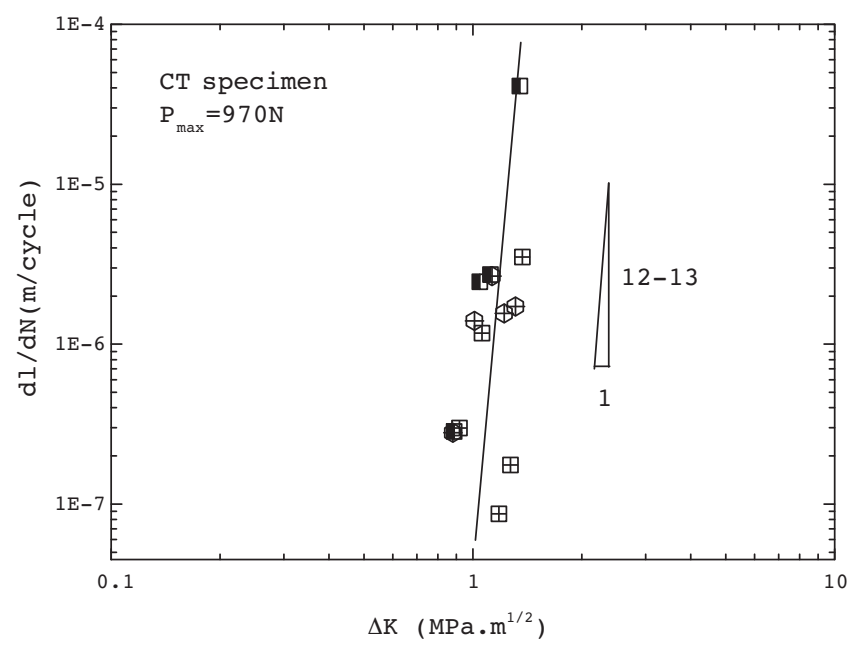

Fig. 11. The fatigue macrocrack growth rate versus the SIF range.

line indicates the exponent parameter associated with the SIF range $\Delta K$, which is found to be between 12 and 13 . Hence, although there are some differences in the fatigue macrocrack length data (i.e. the propagation life), the fatigue macrocrack growth rate can still be expressed as the function of the SIF range, showing that the macrocrack propagation is mainly determined by $\Delta K$.

\section{Results analysis}

Using the single-edge-notch specimen, the fatigue microcrack growth rate was obtained as shown in Fig. 5, and using the CT specimen the fatigue macrocrack growth rate was obtained as shown in Fig. 9. As a crack always starts from a microcrack, it is expected that the fracture mechanism of a microcrack would be the same for a macrocrack at the microscopic level. To better review the mechanism of fatigue crack propagation, the fatigue micro- and macro-crack growth rate curves are combined together in Fig. 12. It can be seen that the fatigue crack growth rates follow the same trend from the micro scale to the macro scale. When the maximum load is less than $900 \mathrm{~N}$ and the SIF range is below 0.8-1.1 MPa.m ${ }^{1 / 2}$, the fatigue crack growth rates for both microcracks and macrocracks are very low, in the range of $10^{-9}$ to $10^{-8} \mathrm{~m} /$ cycle. With the increase of the load level, i.e. increase of the SIF range, the fatigue crack growth rate increases dramatically by up to three orders of magnitude.

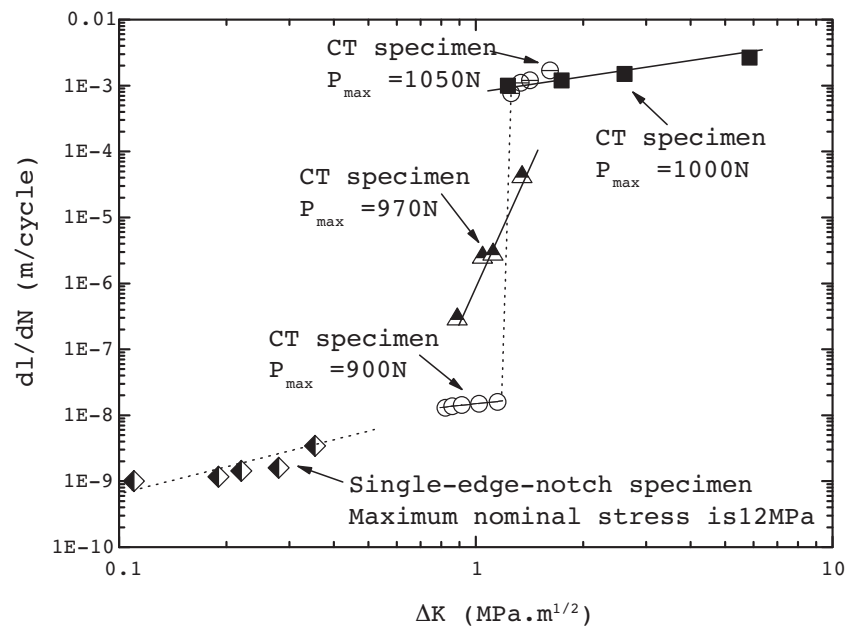

Fig. 12. The fatigue crack growth rates for both micro- and macro-cracks.

Note that the fatigue microcrack growth rate in Fig. 12 was obtained from a specimen without distracting defects near the notch, while for other single-edge-notch specimens no stable crack propagation was observed due to the influence of random microstructures. In Fig. 12, the agreement between the "perfect" microcrack growth rate and the macrocrack growth rates indicates that although microstructures have significant impact on microcrack growth, they do not affect much the macrocrack propagation.

The fatigue crack propagates very fast for the $1000 \mathrm{~N}$ and $1050 \mathrm{~N}$ loading cases, and the CT specimens broke within tens of load cycles. This indicates that this stress level can be used as the failure criterion for the graphite material. If the crack length reaches $6 \mathrm{~mm}$ (while the original notch length of the CT specimen is $8 \mathrm{~mm}$ ), the fatigue crack will form a rapidly developing major crack and cause the specimen to break suddenly.

There is an abrupt change of the fatigue crack growth rate under the maximum load between $900 \mathrm{~N}$ and $1000 \mathrm{~N}$, as shown by the dotted line in Fig. 12. To verify this judgment, the intermediate load level with the maximum load of $970 \mathrm{~N}$ was chosen to perform the same test, and the results are shown in Fig. 12. The exponent parameter of the crack-tip SIF range $\Delta K$ is very large ( $n=11.68$ as shown in Table 2). This confirms that a significant change of the fatigue crack growth rate occurs under this load level, and this provides a link between the results of $900 \mathrm{~N}$ and $1000 \mathrm{~N}$.

Fig. 12 provides very useful information for engineering applications. When the crack-tip stress intensity factor range $\Delta K$ is less than $0.8 \mathrm{MPa} \mathrm{m}^{1 / 2}$, a fatigue macrocrack is controllable. When $\Delta K$ is large than $1.1 \mathrm{MPa} \mathrm{m}^{1 / 2}$, the macrocrack will propagate fast until the component is broken. For specific engineering applications, the associated critical stress can be derived from $\Delta K$.

\section{Fracture analysis}

Fracture surfaces of the graphite material are newly formed faces produced by static or cyclic external forces. Although each fracture surface is different, the surface topography records contain, to some extent, information of crack initiation and propagation. The characteristics of fracture surfaces are affected by various internal and external factors including the composition and microstructure of the graphite material, the external loads and the loading process etc. Analysis of fracture surfaces can help to distinguish different fracturing processes and to understand fracture mechanism from the macro and micro scales.

Some typical fracture surface SEM images of the single-edgenotch specimens are listed in Fig. 13. A complete fracture surface 

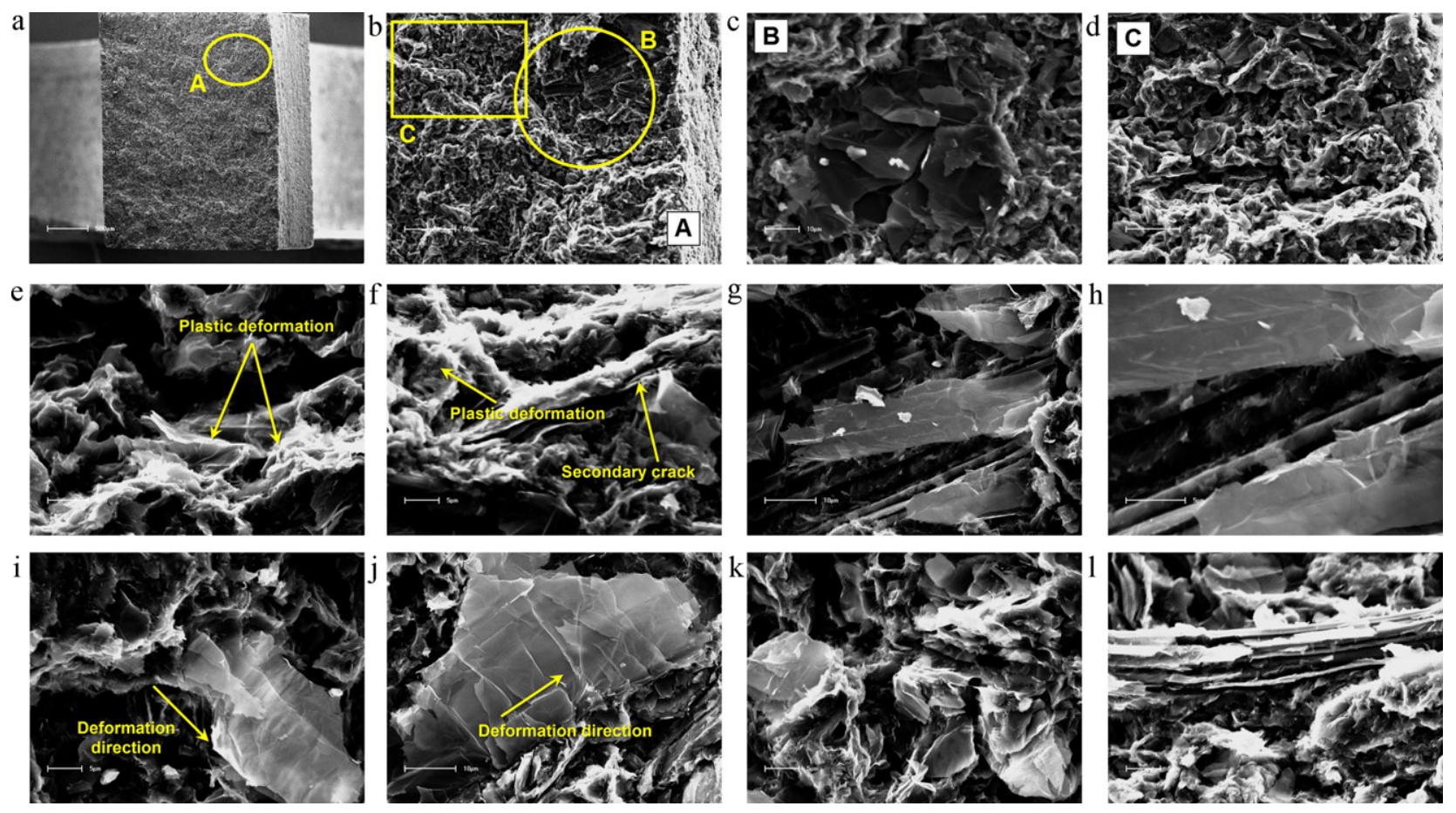

Fig. 13. SEM images of facture surfaces.

is shown in Fig. 13(a), in which the depth of the prefabricated notch covers about $1 / 5-1 / 6$ of the facture surface. Unlike the fatigue fracture surfaces of metals, no clear fatigue propagation region can be observed at the macroscale. However, when zooming in, some interesting microscale features can be identified, as shown in Fig. 13(b-l). Fig. 13(b) shows the enlarged view of region A near the notch in Fig. 13(a). Fig. 13(c) and (d) shows the enlarged views of regions $B$ and $C$ in Fig. 13(b).

(1) At the micro scale, there exist sliding regions consisting of a large number graphite flakes, as shown in Fig. 13(i and j). Also, some small cotton-shape plastic deformation can be observed, as shown in Fig. 13(e and f).

(2) As shown in Fig. 13(c), the fracture mode of some unit cells forms approximately as a hexagon shape, and the sizes of these fractured unit cells range from 30 to $100 \mu \mathrm{m}$.

(3) In Fig. 13(e and f), significant amount of secondary cracks and sliding traces of graphite flakes are observed both within the unit cell and along the cell surface. In particular, with a random distribution, the secondary cracks occur mainly inside graphite flakes or on their interfaces. This indicates that the fatigue fracture mechanism of the graphite material is a mixture of transcrystalline and intercrystalline fracture behaviors, i.e. the so called cleavage fracture.

(4) There are a large number of micro voids inside the graphite material, which cannot hold any loads.

(5) Considerable sliding of graphite flakes can be observed in Fig. 13(i and $j$ ). The characteristics of these leaf-shape flakes indicate that the graphite material has been torn out in these regions. Specifically, the fracture surfaces are clearly higher than the fractured wall of the unit cells, and the sliding traces are inclined at an angle of $45^{\circ}$, following the direction of the maximum shear force.

(6) Neither at the sample scale nor at the microstructure scale, can clear initiation point/line of fatigue cracks be identified.

The characteristics of the facture surfaces from other specimens are similar to the above specimen. It can be seen that the

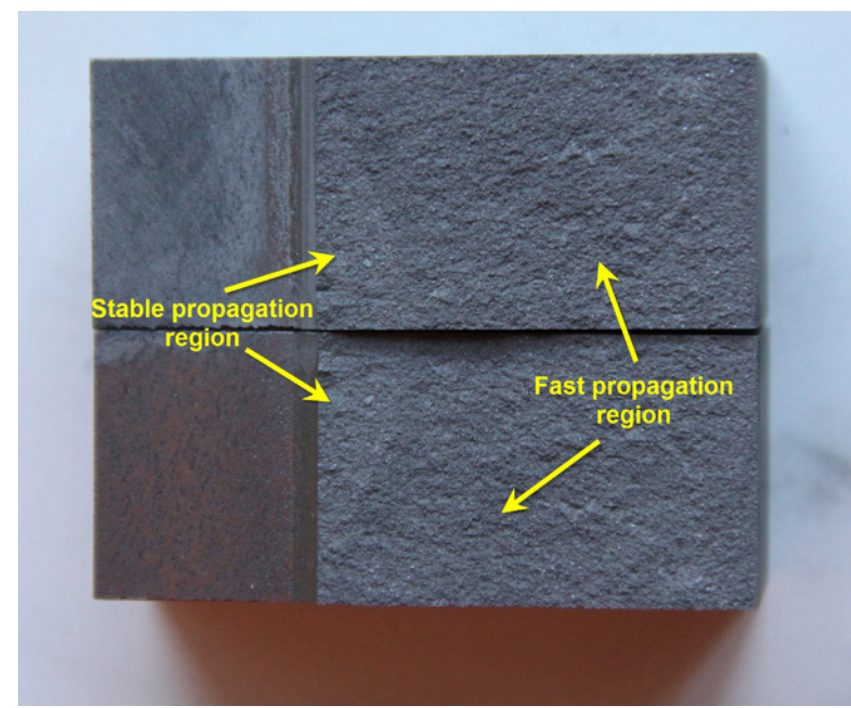

Fig. 14. Facture surfaces of a CT specimen.

fatigue microcrack growth path, whose length is about $100 \mu \mathrm{m}$, coincides with the facture of the cell wall and the structure of the unit cell. That is, the fatigue microcracks mainly propagate at the same length scale of unit cells.

Shown in Fig. 14 are a pair of facture surfaces of a CT specimen. As indicated by the yellow arrows on the figure, both a stable propagation region (next to the sharp notch) and a fast propagation region can be observed. Unlike metal materials, no clear plastic deformation can be identified. This implies that at the macro scale, fatigue crack growth of graphite is similar to brittle materials. The fracture surface of the CT specimen demonstrates the behavior of macro fatigue crack growth, while the fracture surface of the single-edgenotched specimen describes the behavior of micro cracks, i.e. the initiation of macro cracks. 


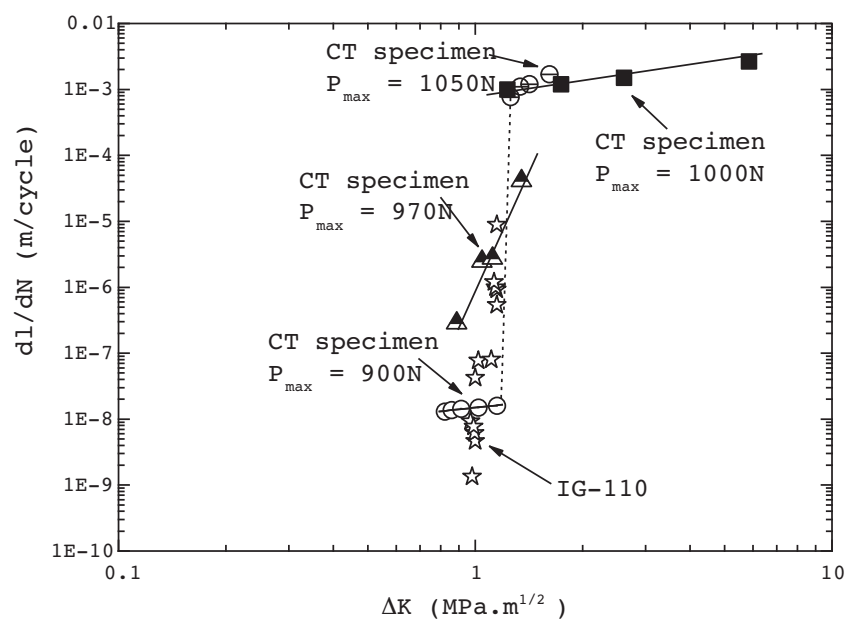

Fig. 15. Comparison between our test results and the results obtained by Shintarou et al. (1991).

\section{Discussion and comparison}

Crack growth rates of different graphite materials have been studied in Shintarou et al. (1991), Marshall and Priddle (1973), Kakui and Oku (1986), Thiele et al. (1983), Shaw and Bacon (1993) and Tad et al. (1994) using different methods. In Fig. 15, the fatigue data corresponding to the SIF threshold $K_{\text {th }}=0.92 \mathrm{MPa} \mathrm{m}^{1 / 2}$ in reference Shintarou et al. (1991) are integrated together with our test results under the same measuring scale. It can be seen that the test result obtained for IG-110 graphite (Shintarou et al., 1991) fall into the transition region close to the dotted line, showing good agreement with our test results.

As shown in Fig. 15, the crack propagation of IG-11 graphite can be classified into three stages. In the first stage, when the crack-tip SIF range $\Delta K$ is below a threshold (about $0.8 \mathrm{MPa} \mathrm{m}^{1 / 2}$ ), the crack growth rate is very low (in the range of $10^{-9}$ to $10^{-8} \mathrm{~m} /$ cycle) and does not change much when the stress level increases. In the second stage, when $\Delta K$ reaches the threshold value, the crack growth rate increases dramatically within a very narrow band by several orders of magnitude. In the third stage, when $\Delta K$ is above the threshold value (about $1.1 \mathrm{MPa} \mathrm{m}^{1 / 2}$ ), the crack growth rate stabilizes at a high level and the crack propagates very fast causing the material to fail in tens of load cycles.

Similar conclusions are also obtained by other researchers in the study of crack growth resistance. From the $R$ curves in $\mathrm{Li}$ et al. (1999), Fazluddin (2002), Shi et al. (2008), Hodgkins et al. (2004), Hodgkins et al. (2006) and Ouagne et al. (2002), the fracture SIFs $K_{R}$ for different graphite materials are found to be in the range of $0.8-1.2 \mathrm{MPa} \mathrm{m}^{1 / 2}$. Especially in Ouagne et al. (2002), the $K_{R}$ curves for controlled crack propagation in CT specimens also contain three stages, with a flat second stage where $K_{R} \approx 1.18 \mathrm{MPa} \mathrm{m}^{1 / 2}$. This plateau region indicates that when the crack length of PGA graphite is in the range of $8-25 \mathrm{~mm}$, its stress intensity factor only changes slightly. Viewing this result in the context of fatigue fracture, it can be seen that the SIF range does not change much with the increase of crack growth rate, which agrees well with our observation as shown by the dotted line in Fig. 15. The initial crack propagation $(0-10 \mathrm{~mm})$ and the final crack propagation before failure $(25-30 \mathrm{~mm})$ in reference Ouagne et al. (2002) are also in good agreement with our test results for the first and third stages. In reference Fazluddin (2002), the $K_{R}$ curves for IG-110 graphite were obtained by three-point bending and compact tension tests. It was found that the $K_{R}$ value changes slightly in the range of $1.00-1.05 \mathrm{MPa} \mathrm{m}^{1 / 2}$ while the crack propagates very fast almost reaching unstable crack growth. These results also support our observations.

\section{Conclusions}

For IG-11 graphite, the fatigue microcrack propagation was investigated using single-edge-notch specimens and in situ SEM measurements, and the fatigue macrocrack propagation was investigated using $\mathrm{CT}$ specimens. The propagation of microcracks corresponds to the initiation of macrocracks. From the test results, the following conclusions can be made:

(1) At the micro scale, the fatigue crack propagation is very sensitive to the microstructure of the graphite material, which makes it very difficult to obtain stable crack propagation. The crack growth rate was only successfully measured for one specimen, in which there were no distracting defects near the main observed crack, and its relationship with the crack-tip SIF range was expressed as a Paris formula.

(2) The fatigue macrocrack growth rate was obtained using CT specimens, and in the first stage with the SIF range under $0.8 \mathrm{MPa} \mathrm{m}^{1 / 2}$, it follows the same trend indicated by the fatigue microcrack growth rate, which was measured from a single specimen without defects near the main crack. This observation indicates that at the macro scale, the microstructures of the graphite material do not have significant impact on fatigue macrocrack growth.

(3) The curves of the fatigue crack growth rate versus the SIF range show three stages: an initial rising part with a small slope, an abrupt change with a large slope and a final rising part with a small slope similar to the initial part. The fatigue micro- and macro-crack growth rate verses the SIF range can be represented in the form of Paris formulae.

(4) It can be seen from the fracture surface that: (a) considerable sliding of graphite flakes occurs during the fatigue fracture process, and this is combined with small cotton-shape plastic deformation; (b) the fracture mode of some unit cells is shown as hexagon shape along the cell wall, whose sizes vary from 30 to $100 \mu \mathrm{m}$; (c) there are a large amount of randomly distributed secondary cracks inside the unit cell as well as on the cell wall, indicating that the fracture mechanism of the graphite material is mainly cleavage fracture; (d) the sliding trace of the leaf-shape graphite flakes is aligned at $45^{\circ}$, indicating that the fracture is mainly caused by the shear stress.

\section{Acknowledgments}

This work has been supported by the National S\&T Major Project (Grant No. ZX06901). Additional funds were also provided by the National Natural Science Foundation of China (Grant Nos. 11002080,10602029 and 51002084). The authors would also like to thank the support from the Royal Academy of Engineering through the Research Exchanges with China and Indian Award. The authors wish to thank Dr. Xi-Shu Wang in all experimental assistances.

\section{References}

ASTM E647 - 11, Standard Test Method for Measurement of Fatigue Crack Growth Rates. ASTM International, West Conshohocken, PA, http://dx.doi.org/10.1520/E0647-11, www.astm.org, in press.

Fazluddin, S., 2002. Crack growth resistance in nuclear graphite. PhD thesis, Department of Materials, The University of Leeds.

Hodgkins, A., Marrow, T.J., Mummery, P., et al., 2004. Fracture behavior of nuclear graphite. In: 2nd International Topical Meeting on High Temperature Reactor Technology, 22-24 September 2004, Beijing, China.

Hodgkins, A., Marrow, T.J., Mummery, P., et al., 2006. X-ray tomography observation of crack propagation in nuclear graphite. Mater. Sci. Technol. 22 (9), 1045-1051. 
Kakui, H., Oku, T., 1986. Crack growth properties of nuclear graphite under cyclic loading conditions. J. Nucl. Mater. 137, 124-129.

Li, M., Tsujimura, M., Sakai, M., 1999. Crack-face grain interlocking/bridging of a polycrystalline graphite: the role in mixed mode fracture. Carbon 37, 1633-1639.

Li, W.F., Zhang, X.P., 2001. Investigation of initiation and growth behavior of short fatigue emanating from a single edge notch specimen using in situ SEM. Mater. Sci. Eng. A 318, 129-136.

Marshall, P., Priddle, E.K., 1973. Room temperature fatigue crack propagation in reactor graphites. Carbon 11, 541-546.

Ouagne, P., Neighbour, G.B., McEnaney, B., 2002. Crack growth resistance in nuclear graphites. J. Phys. D: Appl. Phys. 35, 927-934.

Saito, S., Tanaka, T., Sudo, Y., et al., 1994. Design of high temperature engineering test reactor (HTTR), JAERI 1332

Shaw, M.R., Bacon, D.J., 1993. The fatigue and impact behavior of reactor graphites. Carbon 31 (1), 35-46.

Shi, L., Li, H.Y., Zou, Z.M., et al., 2008. Analysis of crack propagation in nuclear graphite using three-point bending of sandwiched specimens. J. Nucl. Mater $372,141-151$

Shintarou, I., Tatuo, O., Motokni, E., 1991. Fatigue failure and fracture mechanics of graphites for high temperature engineering testing reactor. J. Nucl. Sci. Technol. 28 (5), 472-483.

Tad, N., Higashiguchi, M., Takatsu, M., 1994. Cyclic fatigue properties of isotropic graphite at elevated temperatures. Carbon 32 (5), 825-831.

Thiele, W., Delle, W., Schubert, F., et al., 1983. Fracture mechanics tests in static and cyclic loading conditions on structure graphite for high temperature reactor plants. KFA report JUL-1831, 1983.
Wang, H.T., Zhou, X.W., Dong, J.L., Sun, L.B., Yu, S.Y., 2009. The effect of stress levels on the coefficient of thermal expansion of a fine-grained isotropic nuclear graphite. Nucl. Eng. Des. 239, 484-489.

Wang, X.S., Fan, J.H., 2004. SEM online investigation of fatigue crack initiation and propagation in notched cast magnesium specimens. J. Mater. Sci. 39 (7), 2617-2620.

Wang, X.S., Fan, J.H., 2006. An evaluation on the growth rate of small fatigue cracks in cast AM50 magnesium alloy at different temperatures in vacuum conditions. Int. J. Fatigue 28, 79-86.

Wang, X.S., Li, Y.Q., 2003. Characterization of the fatigue surface microcrack growth in vicinal inclusion for powder metallurgy alloys. Acta Mech. Solid. Sin. 16 (4), 327-333.

Wang, X.S., Liang, F., Fan, J.H., Zhang, F.H., 2006. Investigations on low-cycle fatigue small crack initiation and propagation mechanism of cast magnesium alloys based on in situ observation with SEM. Philos. Mag. 86 (11), 1581-1596.

Wang, X.S., Xu, Y., 2004. Experiments, characterizations and analysis of a dispersion $\mathrm{U}_{3} \mathrm{Si}_{2}-\mathrm{Al}$ fuel plate with sandwich structure. J. Nucl. Mater. $328(2-3)$ $243-248$.

Wang, X.S., Xu, Y., Xu, X.Q., 2004. Direct observations of microcracking in the fuel plate using the scanning electron microscope. Appl. Compos. Mater. 11 (3), $145-154$.

Wu, Z.X., Lin, D.C., Zhong, D.X., 2002. The design features of the HTR-10. Nucl. Eng. Des. $218(1-3), 25-32$

Zhou, X.W., Wang, H.T., Yu, S.Y., 2011. Anisotropy of coefficient of thermal expansion of nuclear graphite under compressive stresses. Nucl. Eng. Des. 241, 752-754. 